\title{
ESTIMASI PENYERAPAN KARBON HUTAN MANGROVE BAHOWO KELURAHAN TONGKAINA KECAMATAN BUNAKEN
}

\author{
(Estimation of Carbon Absorption at Bawoho Mangrove Forest, Tongkaina \\ Urban Village, Bunaken Regency)
}

\author{
Fihri Bachmid $^{1 *}$, Calvyn F. A. Sondak ${ }^{1}$, Janny D. Kusen ${ }^{1}$
}

1. Program Studi Ilmu Kelautan, Fakultas Perikanan dan Ilmu Kelautan, Universitas Sam Ratulangi Manado.

*e-mail : fihribachmid75@gmail.com

Mangrove forest is one of coastal natural resources that has many ecological, economical and social benefits. One of the benefits is carbon removal and absorption. The purposes of this study were to estimate the potential of carbon removal and carbon dioxide absorption in Bahowo mangrove forest, Tongkaina urban village, Bunaken Regency. Estimation on potential biomass, carbon removal, and carbon dioxide absorption by mangrove trees had been done using four plots $10 \times 10 \mathrm{~m}^{2}$ within distance between $50 \mathrm{~m}$ plot and have been used the allometric equation to estimate the biomass. Every tree within the plot is counted, species and tree diameter ( $\mathrm{dbh}$ ) were recorded. This study found the total biomass was 433.69 tons/ha and carbon removal and carbon dioxide $\left(\mathrm{CO}_{2}\right)$ absorption was 203.83 tonnes $\mathrm{C} /$ ha and 748.07 tons of $\mathrm{CO}_{2}$ /ha respectively.

Keywords : mangrove, biomassa, carbon, global warming

Hutan mangrove merupakan sumber daya alam daerah pesisir yang mempunyai banyak manfaat sangat luas baik secara ekologis, ekonomis, maupun sosial. Tujuan penelitian ini adalah mengestimasi potensi kandungan karbon (C) dan serapan karbondioksida $\left(\mathrm{CO}_{2}\right)$ pohon mangrove Bahowo di Kelurahan Tongkaina Kecamatan Bunaken. Estimasi potensi biomassa, kandungan karbon, dan serapan karbondioksida pada pohon mangrove dilakukan dalam empat plot $10 \times 10 \mathrm{~m}^{2}$ dengan jarak antar plot sejauh $50 \mathrm{~m}$ serta menggunakan persamaan allometrik. Setiap pohon yang ada dalam plot dicatat jumlah, jenis, dan diameternya. Hasil penelitian yang didapat menunjukan total biomassa adalah sebesar 433,69 ton/ha dan hasil estimasi kandungan karbon $(\mathrm{C})$ serta serapan karbondioksida $\left(\mathrm{CO}_{2}\right)$ sebesar 203,83 ton $\mathrm{C} /$ ha dan 748,07 ton $\mathrm{CO}_{2} /$ ha.

Kata kunci : mangrove, biomassa, karbon, pemanasan global

\section{PENDAHULUAN}

Pemanasan global saat ini menjadi isu lingkungan yang utama karena mempunyai dampak yang sangat besar bagi dunia dan berimbas pada kehidupan mahluk hidup, yakni perubahan iklim dan kenaikan permukaan laut (Sunu, 2001).
Pemanasan global merupakan kejadian dimana terjadinya peningkatan suhu di atmosfer, laut dan daratan. Para ilmuwan menyatakan ini disebabkan oleh aktivitas manusia (anthropogenik) dalam melakukan pembakaran bahan bakar fosil, seperti batubara, minyak bumi, dan gas alam yang sangat potensial melepas 
karbondioksida $\left(\mathrm{CO}_{2}\right)$ dan gas-gas lainnya yang dikenal sebagai gas rumah kaca (GRK) ke atmosfer (IPCC, 2003). Ekosistem padang lamun, rawa asin dan mangrove, berperan penting terhadap jumlah total stok karbon (Sondak and Chung, 2015; Nasprianto, et al. 2016).

Hutan mangrove merupakan salah satu ekosistem pesisir perairan tropis yang memiliki beragam manfaat potensial bagi lingkungan dan manusia (Kusen, et al. 2016). Hutan mangrove memiliki salah satu fungsi yang sangat penting sebagaimana hutan lainnya yaitu sebagai penyerap dan penyimpan karbon (C). Hutan mangrove berperan dalam upaya mitigasi akibat dari pemanasan global karena mangrove dapat berfungsi sebagai penyimpan karbon (C) (Bismark, et al. 2008; Sondak, 2015). Hutan mangrove dapat menyimpan lebih dari tiga kali rata-rata penyimpanan karbon per hektar oleh hutan tropis daratan (Donato, et al. 2011). Hal ini didukung oleh penelitian Darusman (2006) dalam Bismark, et al. (2008), bahwa fungsi optimal penyerapan karbon oleh mangrove mencapai $77,9 \%$, dimana karbon yang diserap tersebut disimpan dalam biomassa mangrove yaitu pada beberapa bagian seperti pada batang, daun, dan akar.

Biomassa merupakan total jumlah materi hidup di atas permukaan suatu pohon dan dinyatakan dengan satuan ton berat kering per satuan luas (Brown, 1997). Biomassa pohon dapat dibedakan menjadi dua kategori, yaitu biomassa bagian atas tanah (batang, ranting, daun, bunga dan buah) dan biomassa di dalam tanah (akar). Biomassa pohon berhubungan erat dengan penyerapan karbondioksida
$\left(\mathrm{CO}_{2}\right)$. Simpanan karbon terbesar ada di bagian batang pohon. Bismark, et al. (2008), menyatakan bahwa besarnya biomassa ditentukan oleh diameter, tinggi, dan berat jenis pohon/kayu.

Kandungan karbon pada tanaman menggambarkan seberapa besar tanaman tersebut dapat mengikat $\mathrm{CO}_{2}$ dari udara. Sebagian karbon akan menjadi energi untuk proses fisiologi tanaman dan sebagian masuk dalam struktur tumbuhan dan menjadi bagian dari tumbuhan, misalnya selulosa yang tersimpan pada batang, akar, ranting dan daun (Bismark, et al. 2008). Berdasarkan asumsi Brown (1997) dan IPCC (2003), menyatakan bahwa $45 \%$ sampai $50 \%$ bahan kering tanaman terdiri dari kandungan karbon (C).

Tujuan penelitian ini ialah menghitung biomassa bagian atas (above ground biomass) pohon mangrove, mengestimasi potensi kandungan karbon (C) dan serapan karbondioksida $\left(\mathrm{CO}_{2}\right)$ pohon mangrove. Manfaat dari penelitian ini dapat memberikan informasi ilmiah, dan menjadi acuan untuk kebijakan Pemerintah dalam rencana pengembangan wilayah dan konservasi, serta dapat menjadi data dan informasi yang bisa menjadi refrensi bagi penelitian-penelitian selanjutnya.

\section{METODELOGI PENELITIAN}

Penelitian dilakukan selama 3 bulan, mulai dari bulan Agustus sampai bulan Oktober 2017 di kawasan hutan mangrove Bahowo, Kelurahan Tongkaina, Kecamatan Bunaken (Gambar 1). Cara pengambilan data dalam kegiatan penelitian ini yaitu dengan cara yang tanpa merusak objek penelitian. 

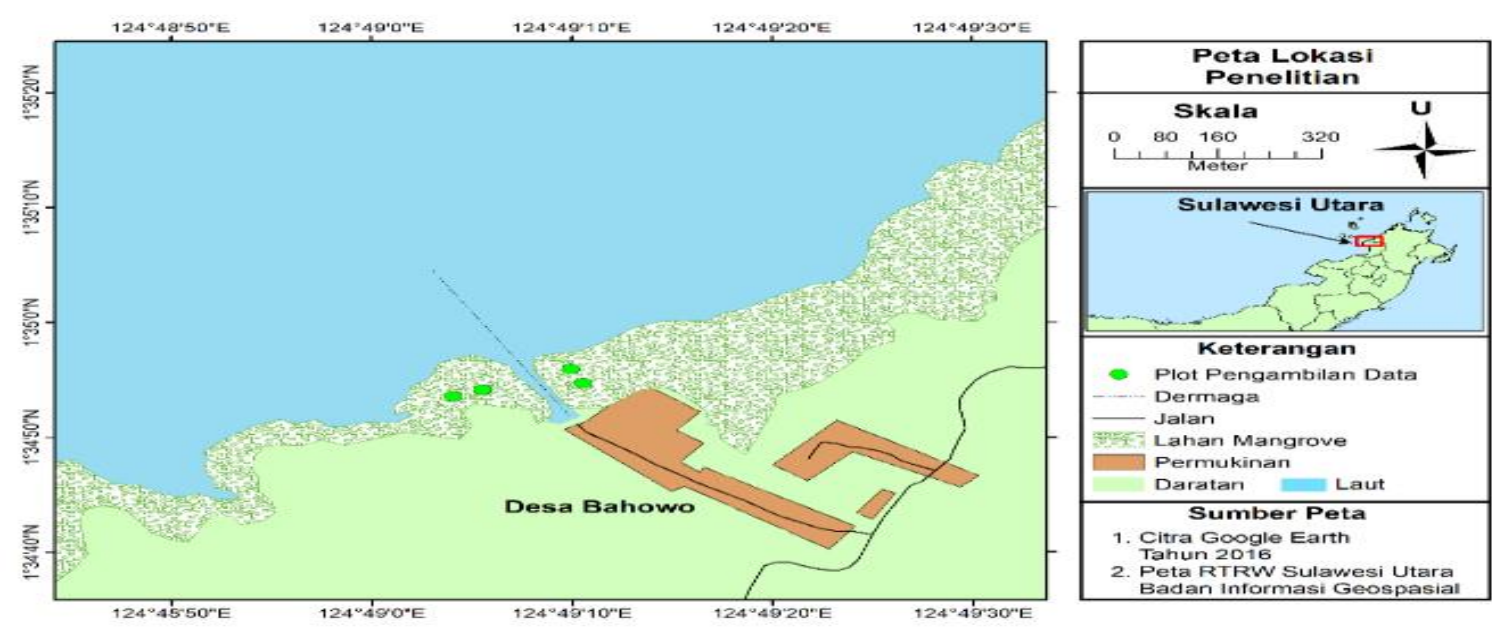

Gambar 1. Peta lokasi penelitian

Pengambilan data dilakukan pada 4 plot berukuran $10 \times 10 \mathrm{~m}$, dengan jarak antar plot sejauh $50 \mathrm{~m}$. Semua pohon yang ada di dalam setiap plot dicatat jumlah, jenis dan diukur DBH-nya (diameter at breast height).

Penghitungan kandungan karbon pada pohon dilakukan tanpa merusak tetapi dengan mengestimasi. Untuk menghitung biomassa pohon digunakan persamaan allometrik dan nilai diameter pohon mangrove sebagai berikut (Komiyama, et al. 2005):

$$
\text { Wtop }=\rho^{*} 0,251 \mathrm{DBH}^{2,46}
$$

dimana:

$$
\begin{aligned}
\mathrm{W}_{\text {top }}= & \text { Biomassa di atas permukaan } \\
& \text { tanah(ton). } \\
\mathrm{DBH}= & \text { Diameter batang pohon yang } \\
& \text { diukur setinggi dada } \pm 1,3 \mathrm{~m} . \\
\mathrm{p}= & \text { Berat jenis pohon } / \text { kayu }
\end{aligned}
$$

Menurut IPCC (2006), konsentrasi karbon yang terkandung dalam bahan organik adalah sebesar 47\%. Maka estimasi jumlah karbon tersimpan yaitu dengan mengalikan 0,47 dengan nilai biomassa seperti pada persamaan berikut:

$$
\mathrm{C}=\mathrm{B} \times 0,47
$$

dimana $: C=$ Jumlah stok karbon (ton) $\mathrm{B}=$ Biomassa

(1999), potensi penyerapan gas karbondioksida $\left(\mathrm{CO}_{2}\right)$ diperoleh melalui perhitungan perkalian kandungan karbon terhadap besarnya serapan karbondioksida $\left(\mathrm{CO}_{2}\right)$ dengan rumus yang digunakan, yaitu :

$$
\mathrm{WCO}_{2}=\mathrm{C} \times \mathrm{FKCO}_{2}
$$

dimana:

$$
\begin{aligned}
\mathrm{WCO}_{2}= & \text { Banyaknya } \mathrm{CO}_{2} \text { yang } \\
& \text { diserap (ton) } \\
\mathrm{C}= & \text { Karbon (ton) } \\
\mathrm{FKCO}_{2}= & \text { Faktor konversi unsur karbon } \\
& \text { (C) ke } \mathrm{CO}_{2}=3,67
\end{aligned}
$$

\section{HASIL DAN PEMBAHASAN}

Dalam peneitian ini ditemukan ada 3 spesies yaitu Sonneratia alba, Rhizophora mucronata, dan Avicennia officinalis. Sonneratia alba mendominasi dalam plot 1, 2 dan 4, sedangkan pada plot 3 didominasi $R$. mucronata. Pada penelitian 
Tabel 1. Biomassa, kandungan karbon (C), dan serapan karbondioksida $\left(\mathrm{CO}_{2}\right)$ hutan mangrove Bahowo, Kelurahan Tongkaina, Kecamatan Bunaken.

\begin{tabular}{cccc}
\hline Plot & $\begin{array}{c}\text { Wtop } \\
\text { (ton/ha) }\end{array}$ & $\begin{array}{c}\text { C } \\
\text { (ton/ha) }\end{array}$ & $\begin{array}{c}\text { WCO }_{2} \\
\text { (ton/ha) }\end{array}$ \\
\hline 1 & 117,07 & 55,02 & 201,93 \\
2 & 85,11 & 40,00 & 146,80 \\
3 & 213,00 & 100,11 & 367,40 \\
4 & 18,52 & 8,70 & 31,94 \\
\hline Jumlah & 433,69 & 203,83 & 748,07 \\
\hline
\end{tabular}

sebelumnya Anthoni, et al. (2017), spesies yang ditemukan berjumlah 3 tetapi spesies yang berbeda yaitu Rhizophora apiculata, $R$. mucronata, dan Bruguiera gymnorrhiza. Dari hasil perbandingan maka jumlah spesies yang di temukan di Desa Bahowo ada 5 spesies.

Dalam penelitian ini dapat terungkap juga bagaimana hutan mangrove dalam menyerap dan menyimpan karbon (C) (Carbon sink). Carbon sink merupakan istilah yang sering digunakan di bidang perubahan iklim. Carbon sink adalah penyimpanan karbon (C) dari atmosfer oleh hutan dan ekosistem laut dalam mengurangi emisi di alam, secara berkesinambungan seperti halnya siklus karbon (C) (Donato, et al. 2011).

$$
\text { Hasil perhitungan biomassa }
$$

pohon mangrove (Tabel 1), menunjukan nilai biomassa sebesar 117,07 ton/ha (Plot 1), 85,11 ton/ha (Plot 2), 213,00 ton/ha (Plot 3), dan 18,52 ton/ha (Plot 4). Biomassa terbesar ada pada Plot 3, oleh karena Plot 3 memiliki rata-rata diameter pohon terbesar.

Menurut IPCC, (2006), konsentrasi karbon yang terkandung dalam bahan organik yaitu sebesar 47\%. Untuk mengestimasi jumlah karbon tersimpan yaitu dengan mengalikan 0.47 dengan nilai biomassa. Hasil estimasi kandungan karbon (C) pohon mangrove (Tabel 1), menunjukan nilai kandungan karbon (C) sebesar 55,02 ton C/ha (Plot 1), 40,00 ton $\mathrm{C} /$ ha (Plot 2), 100,11 ton $\mathrm{C} /$ ha (Plot 3), dan 8,70 ton $\mathrm{C} / \mathrm{ha}$ (Plot 4).

Menurut Murdiyarso, et al. (1999), potensi penyerapan gas karbondioksida $\left(\mathrm{CO}_{2}\right)$ diperoleh melalui perhitungan, perkalian kandungan karbon terhadap besarnya serapan karbondioksida $\left(\mathrm{CO}_{2}\right)$. Hasil estimasi serapan karbondioksida $\left(\mathrm{CO}_{2}\right)$ pohon mangrove (Tabel 1), menunjukan nilai serapan karbondioksida $\left(\mathrm{CO}_{2}\right)$ yang diserap sebesar 55,02 ton $\mathrm{CO}_{2} /$ ha (Plot 1), 40,00 ton $\mathrm{CO}_{2}$ /ha (Plot 2), 100,11 ton $\mathrm{CO}_{2} /$ ha (Plot 3), dan 8,70 ton $\mathrm{CO}_{2} /$ ha (Plot 4).

Biomassa dan kandungan karbon (C) hutan mangrove Bahowo, Kelurahan Tongkaina yang di dapat cukup tinggi sebesar 433,69 ton/ha dan 203,83 ton C/ha. Dibandingkan dengan hutan mangrove Siberut sebesar 32,63 ton/ha $(16,32$ ton $\mathrm{C} / \mathrm{ha})$ (Bismark, 
et al, 2008). Sebagai perbandingan biomassa hutan mangrove Teluk Miskam, Tanjung Lesung sebesar 51,94 ton C/ha Afiati, et al. (2013). Hasil perbandingan dengan kedua penelitian di atas menunjukan bahwa kandungan karbon yang di dapat dalam penelitian ini jauh lebih tinggi.

\section{KESIMPULAN}

Dari penelitian yang dilakukan didapat nilai biomassa bagian atas (above ground biomass) pohon mangrove ialah sebesar 433,69 ton/ha; dan hasil estimasi potensi kandungan karbon (C) sebesar 203,83 ton C/ha; dan serapan karbondioksida $\left(\mathrm{CO}_{2}\right)$ sebesar 748,07 ton $\mathrm{CO}_{2} /$ ha.

\section{DAFTAR PUSTAKA}

Afiati, N.R., Rustam A., Kepel T.L., Astrid, M., Daulat, A. D., Suryono, D., Puspitaningsih, Y., Mangindaan P., Hutahaean, A. 2012. Karbon Stok dan Struktur Komunitas Mangrove sebagai Blue Carbon di Tanjung Lesung, Banten. Keltibang Karbon Biru, Pusat Penelitian dan Pengembangan Sumberdaya Pesisir dan Laut, Balitbang Kelautan dan Perikanan, Kementerian Kelautan dan Perikanan Republik Indonesia. 14 hal.

Anthoni, A., Schaduw, J.N.M., Sondak, C.F.A. 2017. Persentase Tutupan dan Struktur Komunitas Mangrove di Sepanjang Pesisir Taman Nasional Bunaken Bagian Utara. Jurnal Pesisir dan Laut Tropis, 2 (1) : 13-21.

Bismark, M., Subiandono, E., dan Heriyanto, N.M. 2008.
Keragaman dan Potensi Jenis serta Kandungan Karbon Hutan Mangrove di Sungai Subelen Siberut, Sumatera Barat. Jurnal Penelitian Hutan dan Konservasi, 5 (3) : 297-306.

Brown, S. 1997. Estimating Biomass and Biomass Change of Tropical Forest. A Primer, FAO. Forestry Paper No. 134. FAO, USA.

Donato, D. C., Kauffman, J. B., Murdiyarso, D., Kurnianto, S., Stidham, M., dan Kanninen, M. 2011. Mangroves among the most carbon-rich forests in the tropics. Nature Geoscience, 4 (5) : 293-297.

IPCC, (Intergovermental Panel on Climate Change) ${ }_{2}$ 2003. IPPC Guidelines for Nation Greenhouse Inventories : Reference Manual IPCC.

IPCC, (Intergovermental Panel on Climate Change), 2006. IPCC Guidelines for National Greenhouse Gas Inventories, Agriculture, Forestry and Other Land Use. Keith Paustian, N. H. Ravindranath, Andre van Amstel, Michael Gytarsky, Werner A. Kurz, Stephen Ogle, Gary Richards, and Zoltan Somogyi: The Institute for Global Enviromental Strategies (IGES).

Komiyama, A., Poungparn S., Kato S. 2005. Common allometric equations for estimating the tree weight of mangroves. Journal of Tropical Ecology, 21 : 471-477.

Kusen, D. J., Lumingas, L.J.L., Rondo M. (2016). Ekologi Laut Tropis 
Ekosistem Hutan Mangrove. FPIK UNSRAT. 378 hal.

Murdiyarso, D., Purbopuspito, J., Kauffman, J. B., Warren, M., Sasmito, S., Donato, D., Kurnianto, S. 2015. The potential of Indonesian mangrove forests for global climate change mitigation. Nature Climate Change. Vol.5, DOI: 10. 1038 / NCLIMATE 2734.

Nasprianto, D., Mantiri, M.H., Kepel, T.L., Restu, N.A.A., dan Andreas, H. 2016. Distribusi Karbon di Beberapa Perairan Sulawesi Utara. Jurnal Manusia dan Lingkungan, 23(1):34-41.

Sondak, C.F.A. 2015. Estimasi Potensi Penyerapan Karbon Biru (Blue Carbon) Oleh Hutan Mangrove Sulawesi Utara. Jurnal of ASEAN Studies, 1(1): 24-29.

Sondak, C.F.A. and Chung, I.K. 2015. Potential blue carbon from coastal ecosystems in the Republic of Korea. Ocean Science Journal, Doi 10.1007/ s1260-015-001. 50 (1) : 1-8.

Sunu, P. 2001. Melindungi Lingkungan dengan Menerapkan ISO 14001. PT. Gramedia, Jakarta. 